\title{
Quantifying Traffic- and Temperature-Induced Fatigue Damages of Asphalt Pavement
}

\author{
Md Rashadul Islam • Rafiqul A. Tarefder
}

Accepted: 28 September 2014 / Published online: 7 October 2014

(C) Springer New York 2014

\begin{abstract}
Bottom-up fatigue cracking (i.e., alligator cracking) in MechanisticEmpirical Pavement Design Guide (MEPDG) is predicted based on accumulated damage caused by repeated traffic loading only. Since the number of thermal expansion and contraction is small compared to the number of traffic loads, MEPDG does not consider damage due to thermal expansion and contraction in fatigue cracking calculation of an asphalt pavement. However, thermal damage may be significant and possibly causes premature failure of asphalt pavement especially in zones where daynight and yearly temperature variations are relatively large. This study measures thermal fatigue damage at the bottom of an asphalt concrete and hence, the fatigue life of asphalt concrete using data from an instrumentation pavement section on Interstate 40 (I-40) in New Mexico. As a first step, fatigue models are developed for both vehicle and thermal loads based on laboratory beam fatigue test results. In the second step, using the field-measured strain and modulus values, fatigue damages due to vehicle load and temperature fluctuations are determined. Results show that damages due to traffic load and daily and yearly temperature fluctuations are 62,5 , and $33 \%$ of the total fatigue damage, respectively, in 1-year analysis based on a specific site in New Mexico. Therefore, this study suggests that pavement design should consider fatigue damage due to temperature load in addition to damage due to repeated traffic loading.
\end{abstract}

Keywords Asphalt pavement · Fatigue damage - Traffic · Temperature

\section{Introduction}

Fatigue damage is caused by repeated traffic loading. Though damage caused by a single vehicle may be small, the accumulated damage may not be small due to a large number of vehicles per day or year. Based on the same logic, damage due to day-night and yearly temperature differences may be small. However, accumulated damage due to many day-night temperature cycles in a year and several yearly temperature cycles

M. R. Islam $(\bowtie) \cdot R$. A. Tarefder

University of New Mexico, Albuquerque, NM, USA

e-mail: mdislam@unm.edu 
may not be small, specifically, places like New Mexico (NM) where day-night temperature difference is around $20{ }^{\circ} \mathrm{C}$ most of the days in a year. Therefore, it is interesting to understand damages due to diurnal and annual temperature versus damage due to millions cycles of vehicles per year. This study compares trafficinduced fatigue damage with temperature-induced fatigue damage at the bottom of asphalt concrete for the climate conditions of NM.

Repeated daily and yearly temperature fluctuations cause thermal expansion and contraction of hot mix asphalt (HMA) in flexible pavement. These cyclic expansions and contractions (also referred to as thermal loads) may produce severe damage in HMA. For instance, temperature variations at the surface cause thermal fatigue cracks (transverse surface down crack) even though the magnitude of a single low-temperature cycle is not so severe [1-6]. In addition, surface temperature variations also accelerate the vehicle-induced longitudinal surface down crack [7]. Roque et al. [7] showed that temperature causes $33 \%$ of the total damage for longitudinal surface down crack. The abovementioned studies measured the damage due to temperature variations at the surface of HMA.

On the other hand, the effect of temperature variations at the bottom of HMA, which causes cyclic thermal expansion and contraction, is totally neglected to this date because the temperature variations at the bottom of HMA are small compared to the surface. However, fatigue failure of HMA is the most critical design criteria in flexible pavement and horizontal strain at the bottom of HMA under vehicle load is the key parameter to address this fatigue failure of flexible pavement [8, 9]. Moreover, not only does vehicle load produce horizontal strain at the bottom of HMA, but also temperature variations at the bottom of HMA cause a horizontal strain. Therefore, the total fatigue damage should be the sum of vehicle and temperature-induced damages.

The recently developed Mechanistic-Empirical Pavement Design Guide (MEPDG) predicts fatigue performance of asphalt concrete based on tensile strain at the bottom of asphalt concrete due to repeated traffic loads neglecting thermal strain [10]. Bayat and Knight [11] measured daily strain fluctuations as high as 650 micro-strain $(\mu \varepsilon)$ and yearly strain fluctuations as high as $2544 \mu \varepsilon$ per year at the bottom of HMA. Al-Qadi et al. [12] measured the daily thermal strain up to $350 \mu \varepsilon$ at the bottom of surface layer in an instrumented pavement in Virginia. These measured strain values are greater than vehicle-induced strain. Therefore, thermal strain, though small in number, may have significant effect in causing damage to flexible pavement.

Fang and Sargious [13] evaluated the combined effect of repeated loads and low temperature on asphalt pavement's performance using laboratory indirect tensile strength test. The researchers conducted cyclic tests on an asphalt sample at various temperatures $\left(-10\right.$ to $22{ }^{\circ} \mathrm{C}$ ) and concluded that fatigue damage is critical for greater temperature, i.e., $22{ }^{\circ} \mathrm{C}$. However, the thermal expansion and contraction was not considered in that study. Alkaiss and Al-Maliky [14] developed a finite element model (FEM) using commercial FEM software, ANSYS and compared the stress at the bottom of HMA for different values of coefficient of thermal contraction (CTC). The researchers concluded that combined stress due to vehicle and thermal stress at the bottom of HMA increases with an increase in CTC. Damage due to thermal load was not evaluated in that study. Therefore, conclusion can be drawn that past research has not evaluated temperature-induced damage at the bottom of asphalt concrete, which may contribute to the fatigue damage of asphalt pavement. 


\section{Objectives}

The main objective of the present study is to compare the effect of temperature-induced damage (fatigue damage) due to thermal expansion and contraction to the trafficinduced fatigue damage at the bottom of asphalt concrete in flexible pavement. Specific objectives are mentioned below:

1. Predict fatigue life (and damage) of Interstate 40 (I-40) New Mexico (NM) pavement due to traffic load based on a laboratory-developed fatigue model and using the measured stiffness and counted traffic

2. Determine damage due to day-night and yearly temperature-induced strain at the bottom of HMA using the developed fatigue model for thermal load

3. Compare the above-determined vehicle and thermal-induced fatigue damages and separate the contribution of damage due to thermal expansion and contraction of asphalt concrete

\section{Methodology}

In the first step, fatigue damage of I-40 pavement is predicted for vehicle load only, which is the procedure of MEPDG to determine the fatigue life of HMA [10]. The fatigue model is developed in the laboratory using beam fatigue testing. The available fatigue models in the literature are not suitable for this study. The reason is that the present study uses a Superpave (SP) mixture, type SP-III with $35 \%$ reclaimed asphalt pavement (RAP) materials and no fatigue model exists in the literature for this mixture. The developed model has input parameters of HMA modulus and tensile strain at the bottom of HMA. A shift factor is applied to the developed model to transfer the model from laboratory to field performance.

To determine HMA moduli, firstly, the monthly average HMA temperature was measured at 12 different months. Then, beam flexure tests (around 100 cycles) were conducted at these temperatures to determine the initial stiffness at 12 different months. Transverse horizontal tensile strains at the bottom of the HMA were measured at different seasons for different axle loads from December 2012 to November 2013 by horizontal asphalt strain gauges (HASGs). The transverse horizontal strain was considered instead of the longitudinal one as the transverse strain is $20 \%$ greater than the longitudinal strain [15]. Garcia and Thompson [16] measured the transverse strain as 1.5 times of the longitudinal strain. The total traffic number for the year determined from the data of installed Weigh-in-Motion (WIM) Data. Finally, fatigue damage due to traffic load is determined for 1 year of traffic loading.

In the second method, fatigue damages due to day-night and yearly longitudinal thermal strains are determined. Fatigue models are developed for both day-night and yearly thermal loads. The vehicle-induced fatigue model cannot be used for predicting temperature-induced fatigue damage, as the frequency of the thermal load is much smaller than that of the vehicle load. The fatigue model for day-night and yearly temperature cycles are different as each has different magnitude and frequency of loading. The developed model has an input parameter of frequency of loading only. Average day-night and yearly thermal strains are measured from December 1, 2012 to 
December 31, 2013 using the HASGs. Fatigue damages due to day-night and yearly temperature-induced loads are determined for 1 year of day-night and yearly temperature cycles and results are compared with vehicle-induced damage obtained from the first method.

\section{Fatigue Damage Due to Traffic Loading}

\section{Field Strain Data Collection}

Horizontal strain data is collected from the instrumentation section for different axle loads at different periods of the year. These values are used in the fatigue life model to predict the allowable number of load repetitions. The section is located on I-40 east bound lane at the Mile Post 141 near the city of Albuquerque in the state of New Mexico, USA. The section has 14 HASGs, 8 vertical asphalt strain gauges (VASGs), 4 earth pressure cells (EPCs), 3 moisture probes, 6 temperature probes, 3 axle sensing strips, a weather station, and a WIM station. Sensor installations were conducted in collaboration with the National Center for Asphalt Technology (NCAT) at Auburn University and New Mexico Department of Transportation (NMDOT).

The section has four layers as shown in Fig. 1. The surface layer is a 263-mm thick HMA layer composed of SP-III mixture with $35 \%$ RAP materials. HMA layer was constructed in three lifts with thickness of $86.5,86.8$, and $89.6 \mathrm{~mm}$ from the bottom one to the top one. Performance grade (PG) binder 76-22, $4.4 \%$ by weight of the mixture was used. The nominal maximum and the maximum aggregate sizes are 19 and $25 \mathrm{~mm}$, respectively. The base layer is $150-\mathrm{mm}$ thick and composed of granular crushed stone aggregate and $50 \%$ RAP materials. The $200-\mathrm{mm}$ thick subbase layer (locally known as process place and compact (PPC)) is constructed with previous base course and RAP materials. Twelve HASGs were installed at the bottom of the HMA (on top of the base layer). The sensors were arranged in an array of four rows and three columns. The

Fig. 1 Longitudinal profile of the instrumented section

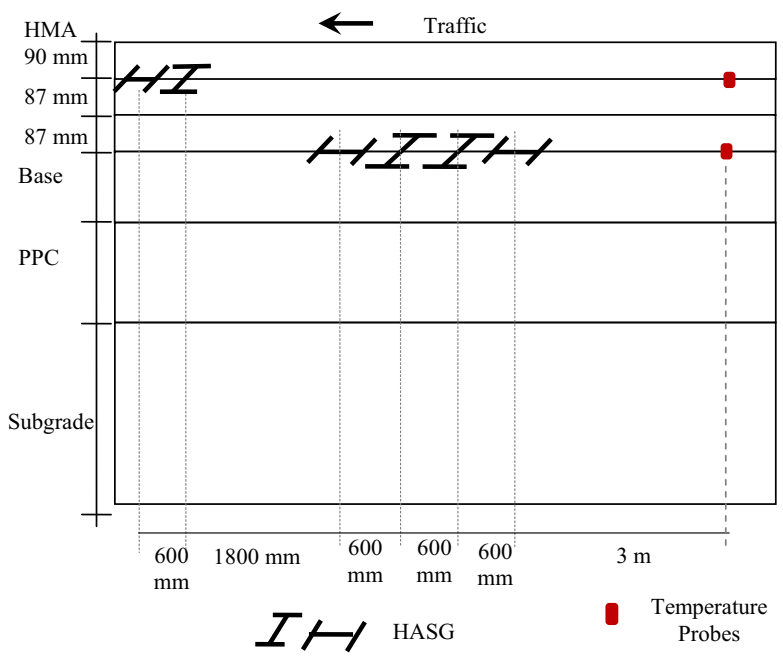


columns were separated by $600 \mathrm{~m}$. All the sensors were also $600-\mathrm{mm}$ apart. The middle two rows of sensors were installed in transverse direction. Two HASGs (one in transverse and one in longitudinal direction) were embedded on the top of the second lift of the HMA at a depth of $90 \mathrm{~mm}$. In addition, temperature probes were also installed at these depths to measure the continuous temperature variations.

\section{Developing Fatigue Model in Laboratory}

The fatigue model is developed in the laboratory using beam fatigue testing following AASHTO T321-07 test protocol [17]. The MEPDG utilizes an approach that models both top-down and bottom-up cracking scenarios [10]. As a first step, the fatigue damages are determined at the surface for top-down cracking and at the bottom of each asphalt layer for bottom-up cracking. The fatigue damage is then correlated to the fatigue cracking using empirical models. Estimation of fatigue damage is based upon Miner's law, which states that damage is given by the following relationship:

$$
D_{R}=\sum_{i=1}^{p} \sum_{j=1}^{m} \frac{n_{i, j}}{N_{f v, i, j}}
$$

where $D_{R}$ is the damage ratio at the end of a year, $n_{i, j}$ is the predicted number of load repetitions for axle type $j$ in period $i, N_{f v i, j}$ is the allowable number of axle load repetitions based on Eq. 1 for $p$ being the number of periods in each year (12 in this study), and $m$ being the number axle groups (1-3 in this study). The allowable number of load repetitions $\left(N_{f v}\right)$ is given by:

$$
\begin{gathered}
N_{f v}=0.007566\left(10^{M}\right) C_{H}\left(\frac{1}{\varepsilon_{t}}\right)^{3.9492}\left(\frac{1}{E}\right)^{1.281} \\
M=4.84\left(\frac{V_{b}}{V_{a}-V_{b}}-0.69\right)
\end{gathered}
$$

where $\varepsilon_{t}=$ tensile strain at critical location, $E=$ stiffness of the material, $C_{H}=$ thickness correction factor, $V_{b}=$ percent effective binder content, and $V_{a}=$ percent air void. While the above fatigue equation can be used to predict fatigue damage, this study performs intensive laboratory study using I-40 material to develop the equation for better accuracy.

Field collected plant produced HMA mixture was used to prepare beam samples using a kneading compactor. Figure 2 shows the preparation of the beam sample in the laboratory. As a first step, beam slabs of $450 \mathrm{~mm} \times 150 \mathrm{~mm} \times 75 \mathrm{~mm}$ were prepared as shown in Fig. 2a and then, each slab was cut into two beams of $380 \mathrm{~mm} \times 63 \mathrm{~mm} \times$ $50 \mathrm{~mm}$ using a laboratory saw as shown in Fig. $2 \mathrm{~b}$. The air voids of the samples range from 5.1 to $5.6 \%$ with an average value of $5.3 \%$. Similar air voids were also observed in the field.

Beam fatigue tests were conducted at $20^{\circ} \mathrm{C}$ using a negative sinusoidal waveform of $10 \mathrm{~Hz}$ with no rest period at different strain levels which are the requirements of AASH 


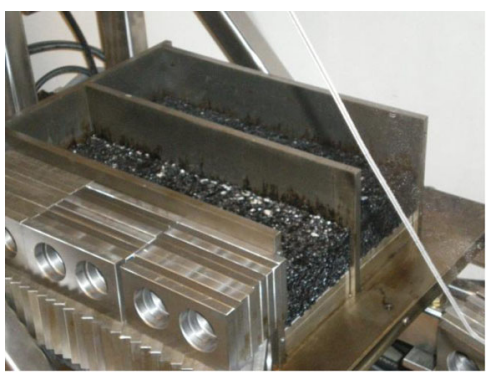

(a) Compacted mixture

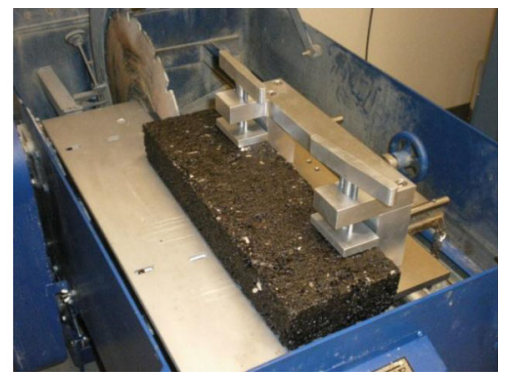

(b) Sample prepared to be cut

Fig. 2 Sample preparations. a Compacted mixture; b sample prepared to be cut

TO T 321-07 test protocol [17]. Negative waveform means that the sample is to be forced to its original position at the end of each load pulse. More clearly, the beam sample is forced downward with sinusoidal loading. Then, the sample is forced to its original position. However, the sample is not forced to bend upward compared to the original position. The test program is shown in Fig. 3a where a sample has been clamped for testing. The middle two clamps are loading clamps which apply downward force to attain certain tensile strain in sample.

Tests were conducted on 60 beam samples at different strains to cover a wide range of horizontal strain that may occur in real pavement. According to the AASHTO T 321-07 standard, the stiffness at the 50th cycle of loading is considered the initial stiffness and the number of cycles at $50 \%$ reduction of initial stiffness is considered the number of cycles at failure. Figure $3 \mathrm{~b}$ shows the test results. The stiffness ratio (current stiffness divided by the initial stiffness) decreases with cycles of loading upon formation of micro-crack. The stiffness decreases very sharply when the initial stiffness is decreased by $50 \%$ due to macro-crack development inside the material. Table 1 lists the different strain levels tested, the average initial stiffnesses, and the average failure cycles along with their standard deviations. At least three replicates have been tested for each category. The tests which took more than 15 days (13 millions of cycles) to finish had been stopped and the data were extrapolated using single-stage Weibull function; this function showed very good performance for the prediction of the number of cycle

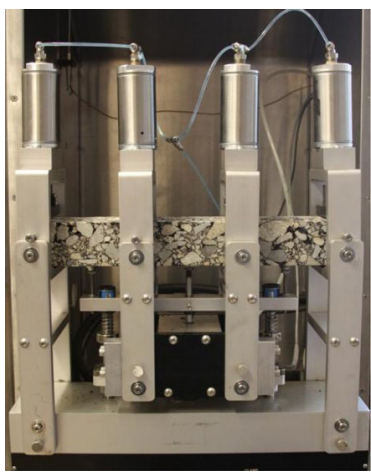

a) Test setup

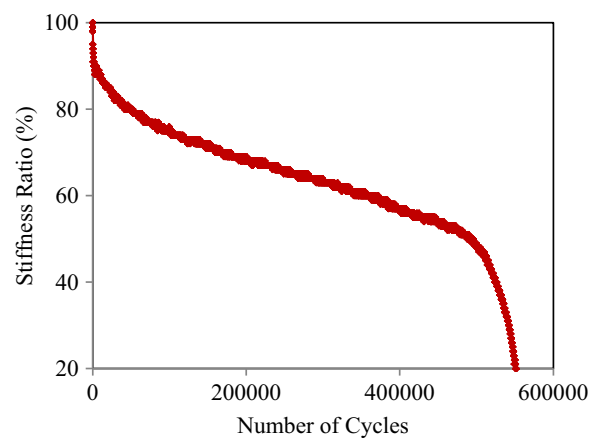

b) Test results

Fig. 3 Flexural stiffness test. a Test setup; b test results 
to fail a sample by extrapolation $[18,19]$. The tests took more than 2 years to finish. It can be found that the stiffness at a particular temperature is not constant. In addition, there is no regular trend of stiffness with applied strain. This is due to the fact that asphalt is not a homogeneous material. Its stiffness is severely affected by the aggregate position, orientation, size, etc. even though the air voids are similar. A larger number of replicate samples may be required to get a clear picture.

The regression equation was developed using the tests results listed in Table 1 . The regression model is presented in Eq. 4, whose coefficient of regression $\left(R^{2}\right)$ is 0.93 .

$$
N_{f v}=0.0006\left(\frac{1}{\varepsilon_{t v}}\right)^{4.36}\left(\frac{1}{E}\right)^{1.1}
$$

where $N_{f w}, \varepsilon_{t w}$ and $E$ are the predicted allowable number of load repetitions for vehicle, transverse tensile strain at the bottom of the surface layer $(\mathrm{m} / \mathrm{m})$, and the initial stiffness of the mixture in psi, respectively.

\section{Measuring HMA Modulus}

The HMA moduli at different seasons were determined at $10 \mathrm{~Hz}$ for different temperatures using beam fatigue test. Firstly, the temperature at the bottom of HMA was measured by installed temperature probes. The minimum and the maximum temperature are measured to be $-2{ }^{\circ} \mathrm{C}$ and $39^{\circ} \mathrm{C}$ in January and June, respectively. Then, beam

Table 1 Beam fatigue test results to develop traffic-induced fatigue model

\begin{tabular}{llll}
\hline Temperatures $\left({ }^{\circ} \mathrm{C}\right)$ & Strain levels (micro-strain) & Avg. E, ksi (MPa) & $N_{f}$ \\
\hline $40{ }^{\circ} \mathrm{C}$ & 50 & $527(3632)$ & $344 \times 10^{6} \pm 2.28 \times 10^{6}$ \\
& 100 & $527(3632)$ & $27.2 \times 10^{6} \pm 0.17 \times 10^{6}$ \\
& 200 & $455(3132)$ & $0.57 \times 10^{6} \pm 26 \times 10^{3}$ \\
& 400 & $283(1949)$ & $0.13 \times 10^{6} \pm 9680$ \\
& 600 & $223(1536)$ & $12.7 \times 10^{3} \pm 1400$ \\
$20{ }^{\circ} \mathrm{C}$ & 800 & $214(1472)$ & $5532 \pm 1100$ \\
& 100 & $944(6504)$ & $23.2 \times 10^{6} \pm 7.1 \times 10^{6}$ \\
& 150 & $960(6614)$ & $9.97 \times 10^{6} \pm 0.33 \times 10^{6}$ \\
& 200 & $1054(7264)$ & $0.43 \times 10^{6} \pm 0.53 \times 10^{6}$ \\
& 400 & $910(6272)$ & $0.05 \times 10^{6} \pm 6500$ \\
$-10{ }^{\circ} \mathrm{C}$ & 600 & $1049(7227)$ & $6390 \pm 2370$ \\
& 800 & $740(5100)$ & $3990 \pm 490$ \\
& 50 & $3188(21996)$ & $97.5 \times 10^{6} \pm 0.53 \times 10^{6}$ \\
& 100 & $2832(19513)$ & $9.3 \times 10^{6} \pm 0.36 \times 10^{6}$ \\
& 200 & $2603(17936)$ & $0.2 \times 10^{6} \pm 0.03 \times 10^{6}$ \\
& 400 & $2705(18635)$ & $0.037 \times 10^{6} \pm 3265$ \\
600 & $2953(20346)$ & $5960 \pm 750$ \\
& 800 & $2850(19635)$ & $2870 \pm 450$ \\
& & &
\end{tabular}


fatigue test was conducted using a negative sinusoidal waveform of $10 \mathrm{~Hz}$ with no rest period at $100 \mu \varepsilon$ strain levels at the measured 12 different temperatures. The measured initial stiffness at the 50th cycle of the loading considered the initial stiffness [17]. The results are listed in Table 2 which is discussed in the next section.

\section{Calculation of Fatigue Damage}

Fatigue life of I-40 pavement is evaluated using the laboratory-developed fatigue model presented in Eq. (1). Table 2 lists the traffic distribution, measured horizontal strain at the bottom of the HMA through the instrumentation section, calculation of damage

Table 2 Calculating fatigue life of pavement for traffic load in the laboratory

\begin{tabular}{|c|c|c|c|c|}
\hline \multirow[t]{4}{*}{ Month } & Stiffness, ksi (MPa) & \multicolumn{3}{|c|}{ Axle loads per year } \\
\hline & & Single axle & Tandem axle & Tridem axle \\
\hline & & $1.13 \times 10^{6}$ & $1.52 \times 10^{6}$ & $0.024 \times 10^{6}$ \\
\hline & & \multicolumn{3}{|c|}{ Measured transverse tensile strain $(\mu \varepsilon)$} \\
\hline January & $2117(14589)$ & 48 & 53 & 59 \\
\hline February & $1672(11517)$ & 68 & 73 & 82 \\
\hline March & $1192(8215)$ & 102 & 109 & 112 \\
\hline April & $890(6132)$ & 132 & 138 & 143 \\
\hline May & $630(4343)$ & 153 & 159 & 163 \\
\hline June & $466(3207)$ & 176 & 209 & 218 \\
\hline July & $475(3270)$ & 198 & 248 & 256 \\
\hline August & $494(3405)$ & 176 & 209 & 218 \\
\hline September & $619(4264)$ & 136 & 186 & 193 \\
\hline October & $963(6633)$ & 102 & 146 & 153 \\
\hline November & $1372(9454)$ & 85 & 105 & 112 \\
\hline December & $1846(12718)$ & 65 & 78 & 86 \\
\hline \multicolumn{5}{|c|}{ Number of cycles at failure, $N_{f v f}=0.0006\left(\frac{1}{\varepsilon_{v v}}\right)^{4.36}\left(\frac{1}{E}\right)^{1.1}$} \\
\hline \multicolumn{2}{|c|}{ January } & $446.22 \times 10^{6}$ & $289.68 \times 10^{6}$ & 181.49 \\
\hline \multicolumn{2}{|l|}{ February } & $126.76 \times 10^{6}$ & $93.03 \times 10^{6}$ & 56.04 \\
\hline \multicolumn{2}{|l|}{ March } & $31.38 \times 10^{6}$ & $23.50 \times 10^{6}$ & 20.87 \\
\hline \multicolumn{2}{|l|}{ April } & $14.068 \times 10^{6}$ & $11.59 \times 10^{6}$ & 9.92 \\
\hline \multicolumn{2}{|l|}{ May } & $10.80 \times 10^{6}$ & $9.13 \times 10^{6}$ & 8.19 \\
\hline \multicolumn{2}{|l|}{ June } & $8.18 \times 10^{6}$ & $3.87 \times 10^{6}$ & 3.22 \\
\hline \multicolumn{2}{|l|}{ July } & $4.79 \times 10^{6}$ & $1.80 \times 10^{6}$ & 1.56 \\
\hline \multicolumn{2}{|l|}{ August } & $7.66 \times 10^{6}$ & $3.62 \times 10^{6}$ & 3.01 \\
\hline \multicolumn{2}{|l|}{ September } & $18.41 \times 10^{6}$ & $4.70 \times 10^{6}$ & 4.00 \\
\hline \multicolumn{2}{|l|}{ October } & $39.70 \times 10^{6}$ & $8.31 \times 10^{6}$ & 6.78 \\
\hline \multicolumn{2}{|l|}{ November } & $59.53 \times 10^{6}$ & $23.69 \times 10^{6}$ & 17.88 \\
\hline \multicolumn{2}{|l|}{ December } & $138.36 \times 10^{6}$ & $62.49 \times 10^{6}$ & 40.82 \\
\hline \multicolumn{2}{|c|}{ Damage ratio $\left(\mathrm{D}_{\mathrm{R}}\right)$ (per year) } & 0.29 & & \\
\hline
\end{tabular}


ratio, and fatigue life prediction. The whole year is divided into 12 months (i.e., January to December). The stiffnesses of the HMA material during these 12 periods were determined using beam flexure test as described in the previous section.

MEPDG [10] calculates the tensile strain at the bottom of HMA using multilayer elastic analysis based on provided traffic load and stiffness. In addition, seasonal variations in stiffness were predicted based on the input climate data, which very often differs from that of the actual construction site. The present study measures the stiffnesses and the tensile strains at the bottom of HMA for different axle loads throughout the year, which is much better than the MEPDG approach. Vehicle classes 1-3 are discarded following MEPDG recommendation [20]. Monthly average tensile strain for each type of axle load is used to calculate the allowable load repetitions.

Using the above-discussed procedure, vehicle-induced fatigue damage and fatigue design life are predicted which is presented in Table 2. The numbers of single, tandem, and tridem axle loads are 1.13, 1.52, and 0.024 million, respectively. HMA stiffness ranges from 465 to $2117 \mathrm{ksi}$ throughout the entire year. Using Eqs. 1 and 5, the vehicleinduced damage ratios of 0.29 per year is obtained. Actually, the laboratory-developed model should be modified to be applicable for field conditions. This is because that laboratory testing does not consider the field traffic speed, rest period, and wheel wander. The effects of these factors have been eliminated by conducting falling weight deflectometer (FWD) on wheel path and shoulder on I-40. Both the wheel path and shoulder have the same geometry and materials.

The decrease in stiffness from the shoulder to the wheel path has been considered the damage caused by traffic load. More specifically, the field damage ratio under the traffic load has been calculated as follows:

$$
D_{R}=\frac{\text { Actual Load }}{\text { AllowableLoad }}=\frac{\text { Stiffness of Shoulder }- \text { Stiffness of Wheel path }}{50 \% \text { of Shoulder Stiffness }}
$$

The numerator of Eq. 5, stiffness of the shoulder minus stiffness of wheel path, denotes the decrease in stiffness due to actual traffic load. The denominator, allowable load, means the number of load repetition needed for failure (50\% reduction of initial stiffness). The reason for $50 \%$ is that asphalt material usually fails when the initial stiffness is decreased by $50 \%$, as shown in Fig. 3.

FWD tests were conducted on wheel path and on shoulder on September 9th, 2013 when the age of the pavement was 1 year (the pavement was allowed for traffic on September 14th, 2012). A total of 15 points have been selected for each case and a total of 15 drops of loads ( 5 drops of 9 kips, 5 drops of 12 kips, and 5 drops of 16 kips) have been applied. The resulting deflections at seven different radials distances for each drop of loads were recorded. The data were analyzed in backcalculation software, ELMOD. The average stiffness of the wheel path and the shoulder are obtained to be 502 and $495 \mathrm{ksi}$ with standard deviations of 6 and $5 \mathrm{ksi}$, respectively. Using Eq. 5, the damage ratio is calculated to be 0.028 per year.

The modification factor (MF) of the laboratory-developed fatigue model for traffic load has been obtained (10.36) by comparing the field damage ratio (0.028) with the 
laboratory damage ratio (0.29). Therefore, the validated fatigue model can be expressed as follows:

$$
N_{f v f}=0.0006 * 10.36 *\left(\frac{1}{\varepsilon_{t v}}\right)^{4.36}\left(\frac{1}{E}\right)^{1.1}
$$

where $N_{f v f}$ represents the number of loading at failure in the field and all other symbols represent the meaning as discussed above. The field damage ratio (0.028) has been used in the final comparison of damages due to traffic and temperature loads.

\section{Fatigue Damage Due to Thermal Loading}

\section{Field Thermal Strain Data Collection}

Thermal strain due to thermal expansion and contraction at the bottom of the HMA was measured from December 1, 2012 to December 31, 2013. The detailed working principle of the strain sensor and separation of thermal strain from traffic-induced strain have been described in another study of Islam and Tarefder [21]. The daily and yearly thermalinduced strain fluctuation is calculated using Eqs. 7 and 8, respectively. The definitions were proposed by Norman [22] and supported by several other researchers [10,11].

$$
\begin{gathered}
\Delta \varepsilon(\text { daily })=\varepsilon_{\text {max }, d}-\varepsilon_{\min , d} \\
\Delta \varepsilon(\text { yearly })=\varepsilon_{\max , y}-\varepsilon_{\min , y}
\end{gathered}
$$

where $\Delta \varepsilon$ (daily), $\varepsilon_{\max , d}$, and $\varepsilon_{\min , d}$ are the daily thermal-induced horizontal strain fluctuation and the maximum and minimum horizontal strains at the bottom of the HMA $(\mathrm{m} / \mathrm{m}) . \Delta \varepsilon$ (yearly), $\varepsilon_{\max , y}$ and $\varepsilon_{\min , y}$ are the yearly thermal-induced horizontal strain fluctuations, and the maximum and minimum horizontal strains at the bottom of the HMA $(\mathrm{m} / \mathrm{m})$, respectively.

The measured thermal strain from December 1, 2012 to December 31, 2013 along with corresponding temperature variations are shown in Fig. 4. Therefore, both strain and temperature data during the above mentioned period are presented. The average value of the monthly day-night thermal strain is calculated for each month. The minimum and the maximum peak-to-peak day-night thermal strain are measured in February $(104 \mu \varepsilon)$ and September $(144 \mu \varepsilon)$, respectively, with an average value of 118 $\mu \varepsilon$. For yearly thermal strain, the minimum and the maximum horizontal strains are -442 to $569 \mu \varepsilon$, respectively, with the peak-to-peak value of $960 \mu \varepsilon$.

\section{Fatigue Model Development}

Fatigue life model for the vehicle load is developed with beam fatigue testing at $10 \mathrm{~Hz}$ as real pavement's fatigue life is better represented at this frequency [23]. However, frequency of thermal load is very low. Usually, it takes $24 \mathrm{~h}$ and 365 days to complete a daily and a yearly thermal cycle, respectively. That means the frequency of day-night and yearly temperature cycles are $1.16 \times 10^{-5}$ and $3.17 \times 10^{-8} \mathrm{~Hz}$, respectively. 


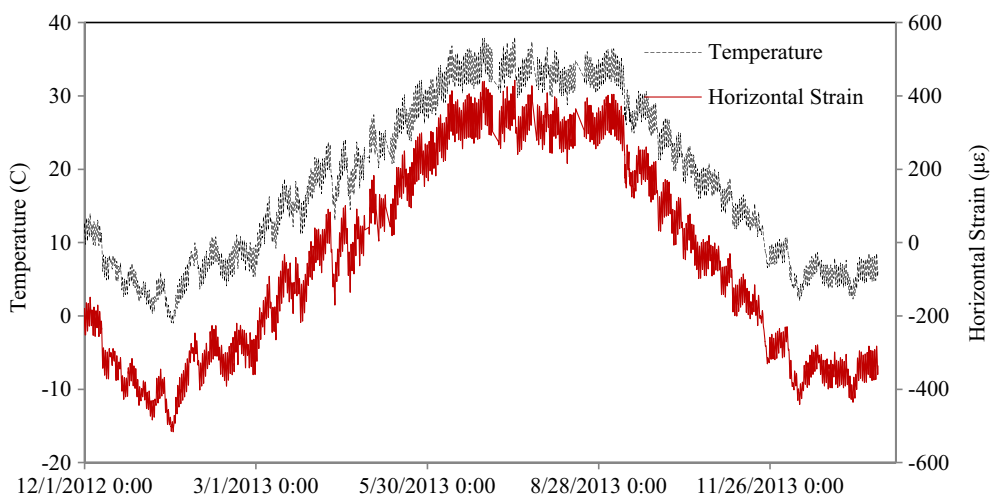

Fig. 4 Temperature and horizontal strain variations at the bottom of HMA

No temperature load was applied to develop the temperature-induced fatigue model. Thermal expansion and contraction produce thermal stress or strain in the material. Applying the mechanical load in a strain-controlled beam fatigue test apparatus attained this equivalent stress or strain. The tests were conducted on beam samples at different low frequencies (up to $0.0001 \mathrm{~Hz}$ ) and different strain levels using positive and negative sinusoidal loading following AASHTO T 321 test standard, and the test results are listed in Table 3. The reason for frequency sweep test is that it is needed to determine the failure cycles at extremely low frequencies such as $1.16 \times 10^{-5}$ and $3.17 \times 10^{-8} \mathrm{~Hz}$ for day-night and yearly temperature cycles, respectively. It was ideal to test the samples at $1.16 \times 10^{-5}$ and $3.17 \times 10^{-8} \mathrm{~Hz}$ to simulate the day-night and yearly

Table 3 Beam fatigue test results to develop thermal fatigue model

\begin{tabular}{|c|c|c|c|c|c|c|c|}
\hline \multirow{2}{*}{$\begin{array}{l}\text { Test temperature } \\
\left({ }^{\circ} \mathrm{C}\right)\end{array}$} & \multirow{2}{*}{$\begin{array}{l}\text { Frequency } \\
f(\mathrm{~Hz})\end{array}$} & \multicolumn{2}{|l|}{$500 \mu \varepsilon$} & \multicolumn{2}{|l|}{$1000 \mu \varepsilon$} & \multicolumn{2}{|l|}{$1500 \mu \varepsilon$} \\
\hline & & $E$ ksi (MPa) & $N_{f}$ & $E$ ksi (MPa) & $N_{f}$ & $E$ ksi (MPa) & $N_{f}$ \\
\hline \multirow[t]{5}{*}{$40^{\circ} \mathrm{C}$} & 10 & $254(1750)$ & 17,560 & $209(1440)$ & 6711 & - & - \\
\hline & 1 & 240 (1654) & 16,990 & 175 (1206) & 2372 & 173 (1192) & 581 \\
\hline & 0.1 & 206 (1419) & 13,700 & $139(958)$ & 3810 & $50(345)$ & 480 \\
\hline & 0.01 & 164 (1130) & 11,330 & $76(525)$ & 3650 & 28 (193) & 361 \\
\hline & 0.001 & $140(965)$ & 10,870 & $51(351)$ & 911 & $13(90)$ & 232 \\
\hline \multirow[t]{5}{*}{$20^{\circ} \mathrm{C}$} & 10 & $1074(7400)$ & 9750 & $736(5071)$ & 3741 & - & - \\
\hline & 1 & $681(4692)$ & 6230 & $511(3521)$ & 2570 & $560(3858)$ & 290 \\
\hline & 0.1 & $670(4616)$ & 3510 & $331(2281)$ & 971 & 305 (2101) & 276 \\
\hline & 0.01 & $250(7400)$ & 2131 & 152 (1047) & 701 & $105(723)$ & 210 \\
\hline & 0.001 & 148 (4692) & 2063 & $82(565)$ & 713 & 33 (227) & 164 \\
\hline \multirow[t]{5}{*}{$-10^{\circ} \mathrm{C}$} & 10 & $2610(4616)$ & 3755 & $2380(16,398)$ & 1203 & - & - \\
\hline & 1 & $2463(1723)$ & 2336 & $1647(11,348)$ & 1136 & $1647(11,348)$ & 79 \\
\hline & 0.1 & $2125(1020)$ & 1935 & $1356(9343)$ & 622 & $1356(9343)$ & 72 \\
\hline & 0.01 & $1793(17,983)$ & 1831 & 1105 (7613) & 348 & 1105 (7613) & 69 \\
\hline & 0.001 & $1642(16,970)$ & 1690 & $656(4520)$ & 342 & $656(4520)$ & 68 \\
\hline
\end{tabular}


temperature cycles, respectively, which is not possible. This limitation has been defeated by determining a calibration factor which is described later.

Using regression analysis, the following fatigue model has been obtained for daily and yearly thermal loads based on the results listed in Table 3 . The $R^{2}$ value of the model is 0.97 which proves the performance of the model.

$$
N_{f t}=2.53 \times 10^{-4}\left(\frac{1}{\varepsilon}\right)^{3.1}\left(\frac{1}{E}\right)^{0.47}(f)^{0.23}
$$

This is the laboratory-developed model. A shift factor is needed to transfer the model to field condition. Twelve beam samples have been restrained with wood as shown in Fig. 5. Then, the restrained samples have been exposed to sun to simulate the real-field condition. In the real field, asphalt concrete is heated up at the surface only and the base material as well as the infinite length of the material makes it restrained. The decreases in stiffnesses of the conditioned samples have been measured at four different cycles of conditioning (i.e., 5, 10, 15, and 20 days). This decrease in stiffness can be considered due to the real-field condition. In real field, the surface of pavement is kept open to sun; the bottom is not. Similarly, the sample was covered with aggregate to so that the top surface is kept open to the sun and the bottom is not. Therefore, it can be assumed that the field conditioning of sample has the similar effect of the real-field effect.

Then, the decrease in stiffness due to the real-field condition has been compared with the bending fatigue test results. To do so, the decreases in stiffnesses under bending load for four different cycles of conditioning (i.e., 5, 10, 15, and 20 days) have been determined at $1.16 \times 10^{-5} \mathrm{~Hz}$ by extrapolating the data presented in Table 3 . The comparison shows that the decrease in stiffness due to real-field condition is an average of 3.98 times less than the bending load in the laboratory for any of four conditioning periods. Therefore, the laboratory thermal model (Eq. 9) has been multiplied by a shift factor of 3.98 to make the model compatible with the field condition.

The fatigue becomes as follows after applying laboratory to field shift factor of 3.98.

$$
N_{f t}=1 \times 10^{-3}\left(\frac{1}{\varepsilon}\right)^{3.1}\left(\frac{1}{E}\right)^{0.47}(f)^{0.23}
$$

where $N_{f t}$ is the number of cycle at failure for thermal load, $\varepsilon$ is the thermal strain, $E$ is the stiffness of HMA in psi, and $f$ is the frequency of loading in $\mathrm{Hz}$.

Fig. 5 Restrained samples to field-condition for thermal damage

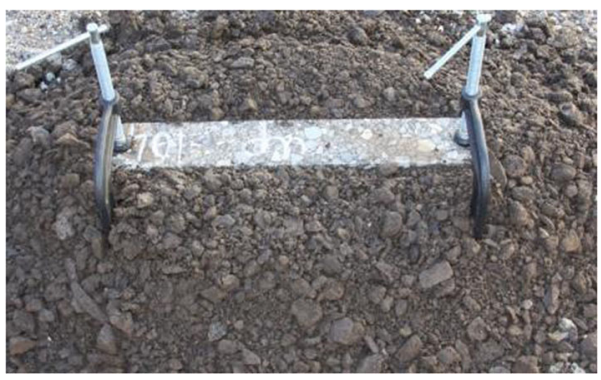




\section{Calculation of Fatigue Damage}

Horizontal strain at the bottom of the HMA should be separated for vehicleinduced strain and thermal-induced strain. The reason is that vehicle-produced strain develops at greater frequency of loading and thermal strain develops at lower frequency. Fatigue life models for both of these strains are completely different. Therefore, the total damage may be calculated based on Eq. 11. Note that the effects of oxidation, healing, moisture, etc. are beyond the scope of this study.

$$
\begin{aligned}
\text { Total fatigue damage }= & \text { vehicle-induced damage } \\
& + \text { daily thermal induced damage } \\
& + \text { yearly thermal-induced damage }
\end{aligned}
$$

To calculate the daily thermal-induced damage, the allowable numbers of load repetitions are obtained using Eq. 9 inserting the $f$ value of $1.16 \times 10^{-5} \mathrm{~Hz}$. The damage ratio is calculated using Miners' hypothesis as presented in Eq. 12 (similar to Eq. 1).

$$
D_{R}=\sum_{i=1}^{12} \frac{n_{i}}{N}
$$

where $\mathrm{D}_{\mathrm{R}}$ is the damage ratio, $n_{i}$ is the number of days of $i$ th month, and $N$ is the

\begin{tabular}{|c|c|c|c|c|}
\hline Periods & $\begin{array}{l}\text { Measured horizontal } \\
\text { strains }(\mu \varepsilon)\end{array}$ & Failure cycles & $\begin{array}{l}\text { Damage ratio } \\
\text { (per year) }\end{array}$ & $\begin{array}{l}\text { Sum of damage } \\
\text { ratio }\end{array}$ \\
\hline \multicolumn{5}{|c|}{ Day-night temperature variations } \\
\hline January & 108 & $0.16 \times 10^{6}$ & $1.99 \times 10^{-4}$ & 0.0021 \\
\hline February & 104 & $0.19 \times 10^{6}$ & $1.48 \times 10^{-4}$ & \\
\hline March & 120 & $0.15 \times 10^{6}$ & $2.11 \times 10^{-4}$ & \\
\hline April & 108 & $0.23 \times 10^{6}$ & $1.28 \times 10^{-4}$ & \\
\hline May & 139 & $0.13 \times 10^{6}$ & $2.47 \times 10^{-4}$ & \\
\hline June & 118 & $0.24 \times 10^{6}$ & $1.28 \times 10^{-4}$ & \\
\hline July & 125 & $0.19 \times 10^{6}$ & $1.55 \times 10^{-4}$ & \\
\hline August & 113 & $0.27 \times 10^{6}$ & $1.15 \times 10^{-4}$ & \\
\hline September & 144 & $0.11 \times 10^{6}$ & $2.73 \times 10^{-4}$ & \\
\hline October & 109 & $0.22 \times 10^{6}$ & $1.41 \times 10^{-4}$ & \\
\hline November & 109 & $0.18 \times 10^{6}$ & $1.67 \times 10^{-4}$ & \\
\hline December & 113 & $0.14 \times 10^{6}$ & $2.15 \times 10^{-4}$ & \\
\hline \multicolumn{5}{|c|}{ Yearly temperature variations } \\
\hline 2012-2013 & 960 & 63 & 0.0158 & 0.0158 \\
\hline
\end{tabular}
allowable load repetitions. To calculate the daily thermal-induced damage, the allowable number of load repetitions (63 cycles) is obtained using Eq. 10 after inserting the

Table 4 Calculation of damage ratios for thermal loads 
Table 5 Comparisons of fatigue damages

\begin{tabular}{ll}
\hline Load type & Damage ratio $\left(D_{R}\right)$ per year \\
\hline Vehicle only & 0.028 \\
Yearly thermal cycle & 0.0158 \\
Day-night thermal cycle & 0.0021 \\
Total $\mathrm{D}_{\mathrm{R}}$ & 0.047 \\
Comparisons & \\
$\quad$ Damage by vehicle loads & $62 \%$ \\
$\quad$ Damage by day-night thermal cycle & $5 \%$ \\
Damage by yearly thermal cycle & $33 \%$ \\
\hline
\end{tabular}

value $f$ as $3.17 \times 10^{-8} \mathrm{~Hz}$. The damage ratio is calculated dividing 1 by 63 as there is only one yearly temperature cycle per year. The damage ratios of both day-night and yearly thermal strain are listed in Table 4 . The sums of the damage ratios of day-night and yearly thermal damage are 0.0021 and 0.0158 per year, respectively. This means that the yearly thermal damage is 7.4 times of the daily thermal damage.

\section{Comparisons of Fatigue Damages}

Vehicle- and thermal-induced damages are compared, which are tabulated in Table 5. It can be seen that fatigue damage ratios produced by traffic and daily and yearly thermal fluctuations are $0.028,0.0021$, and 0.0158 , respectively. It means that $62 \%$ of the total fatigue damage is caused by vehicle load, whereas daily and yearly thermal strain is responsible for 5 and $33 \%$ of the total damage, respectively. This comparison is based on the damages in 1 year of traffic and temperature loads. Due to the nonlinear behavior of damage with age of a pavement, the quantitative comparison conducted herein may change with age.

The results presented in this study are based on the developed fatigue models and measured stiffness in the laboratory and measured strain values in the field from December 2012 to December 2013. The present study, for the first time, explored one important external loading factor (thermal expansion and contraction at the bottom of HMA) in flexible pavement, which should be considered in the design of flexible pavement. However, the results presented in the current study depend on climate of the site, geometry of pavement, materials used, in situ air voids, etc. For instance, thicker surface layer experiences less fatigue damage, stiffer material fails earlier in fatigue, etc. Therefore, ratio of fatigue damage between traffic and temperature varies from site to site and, hence, temperature-induced fatigue damage should be included in the design.

\section{Conclusions}

The present study, for the first time, compares temperature-induced fatigue damage to traffic-induced fatigue damage in asphalt concrete. The damages due to traffic and temperature are dependent on climate, traffic volumes, pavement geometry, etc. This 
study is based on I-40 pavement in New Mexico and only 1 year of analysis was conducted. From the study, the following conclusions can be made:

- Fatigue damage caused by day-night temperature cycles, yearly temperature cycles, and traffic loads are 5,33, and $62 \%$, respectively, for the pavement studied in this study.

- Thermal damage is not negligible compared to vehicle-produced damage to the fatigue life of asphalt concrete. Hence, thermal fatigue damage should be considered in designing asphalt pavement.

Acknowledgments This project is funded by the New Mexico Department of Transportation (NMDOT). Special thanks go to Dr. David Timm of NCAT, Auburn University for his cooperation in the installation of the sensors on the I-40 pavement in New Mexico.

\section{References}

1. Rajbongshi, P.: Comparative study on temperature stresses in asphalt material using nonlinear viscoelastic approach. J. Transp. Eng. 137(10), 717-722 (2011)

2. Underwood, B., Baek, C., Kim, R.: Simplified viscoelastic continuum damage model as platform for asphalt concrete fatigue analysis. Transp. Res. Rec. 2296, 36-45 (2012)

3. Jackson, N.M., Vinson, T.S.: Analysis of thermal fatigue distress of asphalt concrete pavements. Transp. Res. Rec. 1545, 43-49 (1996)

4. Shen, W., Kirkner, D.J.: Distributed thermal cracking of AC pavement with frictional constraint. J. Eng. Mech. 125(5), 554-560 (1999)

5. Timm, D.H., Guzina, B.B., Voller, V.R.: Prediction of thermal crack spacing. Intl. J. Solids Struct. 40, 125-142 (2003)

6. Marasteanu, M., Zofka, A., Turos, M., Li, X., Velasquez, R., Buttlar, W., Paulino, G., Braham, A., Dave, E., Ojo, J., Bahia, H., Williams, C., Bausano, J., Gallistel, A., McGraw, J.: Investigation of Low Temperature Cracking in Asphalt Pavements. National Pooled Fund Study 776. Report No. MN/RC 2007-43, Department of Civil Engineering, University of Minnesota, Minneapolis (2007)

7. Roque, R., Zou, J., Kim, Y., Baek, C., Thirunavukkarasu, S., Guddati, M.: Top-Down Cracking of HotMix Asphalt Layers: Models for Initiation and Propagation. NCHRP Project 1-142, NCHRP Web Only Document 162, NCHRP, TRB of National Academics, Washington, D.C (2010)

8. Mello, L.G.R., Kaloush, K.E., Farias, M.M.: Damage theory applied to flexural fatigue tests on conventional and asphalt rubber Hot mixes. Road Mater. Pavement. Des. 11(3), 681-700 (2010)

9. Sun, L., Hudson, R., Zhang, Z.: Empirical-mechanistic method based stochastic modeling of fatigue damage to predict flexible pavement cracking for transportation infrastructure management. J. Transp. Eng. 129(2), 109-117 (2003)

10. AASHTO 2008: Mechanistic-Empirical Pavement Design Guide. A manual of Practice, July 2008. Interim Edition, American Association of State Highway and Transportation Officials, Washington D. C, (2008).

11. Bayat, A., Knight, M.: Measurement and Analysis of Flexible Pavement Thermal-Induced Strains. Transportation Research Board Annual Meeting 2010, Paper\#10-3654. (2010)

12. Al-Qadi, I., Hassan, M., Elsefi, M.: Field and theoretical evaluation of thermal fatigue cracking in flexible pavements. Transp. Res. Rec. 1919, 87-95 (2005)

13. Fang, Y., Sargious, M.: Combined effect of repeated loads and Low temperatures on asphalt pavements. Can. J. Civ. Eng. 21, 674-681 (1994)

14. Alkaiss, Z.A., Al-Maliky, S.: Combined effects of wheel and thermal load conditions on stress distribution in flexible pavement. Eng. Technol. J. 27(12), 2257-2268 (2009)

15. Islam, M.R., Tarefder, R.A.: Evaluating the longitudinal and the transverse horizontal strains at the bottom of hot mix asphalt. Int. J. Sci. Eng. Res. 4(3), 1-5 (2013)

16. Garcia, G., Thompson, M.: Strain and pulse duration considerations for extended-life hot-mix asphalt pavement design. Transp. Res. Rec. 2087, 3-11 (2008) 
17. AASHTO T321-07: Determining the fatigue life of compacted hot-mix asphalt subjected to repeated flexural bending." Standard specifications for transportation materials and methods of sampling and testing. American Association of State Highway and Transportation Officials, Washington (2007)

18. Prowell, B., Brown, E.R., Daniel, J., Bhattacharjee, S., Von Quintus, H., Carpenter, S.H., Shen, S., Anderson, M., Swamy, A.K., Maghsoodloo, S.: Endurance limit of hot mix asphalt mixtures to prevent fatigue cracking in flexible pavements." Updated draft final report, NCHRP 9-38. National Cooperative Highway Research Program, Washington (2008)

19. Tarefder, R., Barlas, G.: Determining Fatigue Endurance Limits of New Mexico Asphalt Mixes for Designing Perpetual Pavements and Implementation of MEPDG to its Full Capacity. Final Report, NM11MSC-02, 2013, Submitted to the New Mexico Department of Transportation, Albuquerque, NM (2013)

20. Huang, Y.: Pavement analysis and design, 2nd edn. Pearson Prentice Hall, NJ (2004)

21. Islam, M.R., Tarefder, R.A.: Determining coefficients of thermal contraction and expansion of asphalt concrete using horizontal asphalt strain gage. Adv. Civ. Eng. Mater. ASTM 3(1), 204-219 (2014)

22. Norman, D.: Mechanical behavior of materials: engineering methods for deformation, fracture, and fatigue. Prentice Hall, Upper Saddle River (2009)

23. Bateman, D.: Laboratory Investigation of Fatigue Endurance Limits in Asphalt Concrete. Doctoral Dissertation, Department of Civil Engineering, University of New Mexico, Albuquerque (2012). 